\title{
Problem of environmental safety during construction (analysis of construction impact on environment)
}

\author{
Elena Smirnova ${ }^{1,{ }^{*}}$ and Yuliya Larionova ${ }^{2}$ \\ ${ }^{1}$ Saint Petersburg State University of Architecture and Civil Engineering, 4, Vtoraja \\ Krasnoarmejskaja str., 190005, St. Petersburg, Russia \\ ${ }^{2}$ Moscow State University of Civil Engineering (National Research University), 26, Yaroslavskoye \\ shosse, 129337, Moscow, Russia
}

\begin{abstract}
The article provides an analysis of construction influence on the environment, the environment-forming function of the construction activity has also been studied. The assessment of environmental factors has been made on the basis of interdisciplinary approach. The conducted assessment of state and dynamics of eco-economic interaction between the construction activity and the environment, the basis of sustenance of the urban and agricultural economy in Russia, has demonstrated the investment potential of production of the construction materials. However, the raw materials are mined by the open pit; the lands of agricultural purpose get requisitioned for the pits. All this shows an ecological inefficiency of the construction industry growing from year to year. A direct demolition of natural ecosystems in the local areas contradicts the attractiveness of ecological construction in the framework of movement to the sustainable development of the country. The system "construction - vital activities environment" has been reviewed as an eco-economic equilibrium, as a criterion of the authentic system-level development. It is necessary to increase the quality of ecological monitoring. The performed analytical helps to come to a conclusion that notwithstanding the developed basic provisions of institutional policy a negative impact of construction on the environment impedes the development of ecologically-oriented investment and construction activity and sustainable development of the country.
\end{abstract}

\section{Introduction}

It is commonly known that the system of ecological monitoring should accumulate, systematize and analyze information:

- on the state of environment;

- on the reasons of observed and probable changes of its state;

- on admissibility of changes and impacts on the environment as a whole;

- on the existing resources of biosphere.

\footnotetext{
* Corresponding author: esmirnovaee@mail.ru
} 
Thus, the system of ecological monitoring includes observations of the state of biosphere elements and observations of the sources and factors of human impact. One of such major factors is the modern construction. It builds up and develops the human life and activities environment performing creative functions for providing economics with the fixed assets. In turn, the favorable environment of human life and activities and business is used as a matter of course as the basis for health and working ability of people, economical growth of the state as a whole according to the Town-planning code of the Russian Federation N 190-FZ (last revised, August 2, 2019).

The environment is an integral component for making the construction products both in respect to its "releasing" function (natural conditions and resources are meant), and in respect to the "receiving" function (it goes about distribution and assimilation of waste and contaminants). Therefore, the functions are not equal. The "releasing" function of nature is related to the creation of construction facilities of different purpose, it is used for estimated justification and enhancing the level of people protection as a whole, including the system of life sustenance of urban economy and agriculture [1]. On the contrary, the natural world is unprotected in its "receiving" function, most frequently the principles of ecological safety are not regarded, while the ecologically safe construction and operation of the urban economy are not referred to as the imperatives of sustainable development. N.F. Rejmers offers to give consideration to the environment as a dynamic aggregate of the natural environment ("the first nature"), man-modified natural environment ("the second nature"), remediated environment of the towns ("the third nature"), social-psychological and socio-economic environments [2]. Though, even in this case "the first nature" experiences a negative impact on the part of the anthropogenic factor. Since there is no degree of protection of the natural environment, today the urban environment is degraded, the open spaces in the residential construction is desolate, functionally not disjointed, nonhuman-scaled, total expansion of motor vehicles can be observed everywhere [3-4]. The man-induced and psychological impacts grow stronger in the towns. Specifically, it concerns the metropolitan cities, which are understood as the gigantic multimillion cities. An excessive concentration of people, industry, city transport and generation of industry-related landscapes escalate the danger of habitation in the remediated environment. A metropolitan city enhances the instability of the environment, while the use of the up-to-date media, such as TVs, phones, laptops, tablets with the use of Wi-Fi, etc., will bring about an enhancement of the information dependency and the divorce of people from the real life. The ecological crisis will gain momentum more and more until we negate one Christian fundamental truth, according to which the nature is intended for one and the only goal - to serve a human being [5]. In order to preclude the expanding environment pollution, poverty and fast growth of human population, and other negative factors of anthropogenic character, it is necessary to establish and develop the system of ecological monitoring, meet the requirements of environmental regulations and quality standards of the environment.

The world community is actively discussing how to attain a sustainable inexhaustible development of economy. But the soil literally becomes very shaky under the feet of people. The descendants will face a natural and resource distress as well as depletion of natural resources as a result of the present-day human impacts. It is going to be replenished by slow degradation of nature. If it is still more or less simple for an individual to change, and slow down the rate of negative impact of the economic activity on nature using the administrativeeconomic methods, it is impossible to make the atoms of chemical substances move in a somewhat different way, other than it is treated by the Vernadsky law. One may only attempt to preserve the biogeochemical cycles. In order to do so, the world biota species composition should be kept in relative integrity and be preserved.

It should be noted that the approaches to ecological assessment of the construction produce according to ISO-14000 standards take account of the influence of the processes of 
extraction of raw materials, fabrication of construction materials, construction itself, demolition, disposal or recycling of the construction waste on the environment [6-7]. At that, explicit direct impacts (emission of harmful substances, waste generation, etc.) and indirect effects (raw material shortage, influence on human health, aggravation of quality of environment, etc.) will be assessed at all stages of the construction produce life cycle. Presently, the significance of indirect results of construction influence on the environment increases, especially in the long-term period, when the accumulation law and, moreover, the synergizing effect enters into force [8-10].

They distinguish a group of ecotoxicants posing a special danger for the living organisms among the products polluting the environment. It includes the substances that are allogenic for the living organisms, in this case featuring the toxic properties. The ecotoxicants of the "dirty dozen" include heavy metals and the compounds thereof (lead, mercury, cadmium, zinc, etc.), radionuclide, oil and oil products, pesticides and herbicides, surface-active agents and polychlorinated biphenyls [11].

All directions of impact of up-to-date construction technologies, which bear the prime responsibility for aggravation of the state of environment and the results of investigating these impacts are presented sufficiently completely in the works [12-19].

\section{Materials and Methods}

The analysis of state and trends of construction impact on the environment is based on the experience of identification of system-level processes. The genesis of the very "construction" concept consisting of the stages of "building" into environment is used as a basis of the offered concept. Thus, the "construction-environment" system can be extended to a complex dynamic formation within the boundaries of the area of construction influence on the environment, which is expressed in the change of its quality. The principles of ecological safety and sustainable development worded by B. Commoner [5] should be acknowledged as one of characteristics significant for analysis. Let us enumerate these principles: "everything is associated with everything", "everything should disappear somewhere", "nature knows better", "one must pay for everything". It is of prime importance when studying the problem of the man-made impact of construction on the nature to take into account that the active transformations of the ecological environment, biogeocenosis, as well as the extermination of plants and animals by a human-being can bring about an irreversible effect, as a result of which the world will stop to be suitable for the existence of the mankind. The saving of costs for the environment protection and for ecological safety turns for a person into health problems, natural disasters and reduction of favorable conditions for life. In this context for the sake of solving the problem of environment it is not unreasonable to speak of the investment potential of ecological construction, which objects should be regarded as the innovation produce with some specific features [20-21]. In order to provide for dynamic sustainable development of eco-economic "construction-environment" system under conditions of the expanding production and non-production consumption of natural resources, it is necessary to provide an extended reproduction of the nature-resource and ecological potentials at the rate quicker than the economical potential is reproduced [22-23]. On the contrary, the victory and progress of the industrial technologies at one place will inevitably turn into defeat at the other: the self-amplifying process of demolition of natural organisms is supplemented by degradation of the immediate environment of human life and activities [24].

In order to build the conceptual model, a function approach has been applied to provide formal grounds for synthesis of the system-level components. This approach makes it possible to model every nodal system component and integrate these into a unified complex according to the structure of the conceptual model. The authors also follow the principles of 
the dynamic model of D. Meadows [25] based on 5 principal indicators: 1) accelerating industrialization, 2) population growth, 3) multiplication of the undernourished, 4) depletion of resources, 5) aggravation of environment. It is important to consider the fundamental significance of the second biogeochemical law of V.I. Vernadsky [26]: migration of chemical elements in the biosphere takes place with the mandatory direct or indirect participation of the living organisms, in other words, the migration of chemical elements across the earth's surface and in the biosphere takes place in general with direct participation of the living matter or, otherwise, it proceeds in the environment, which geochemical features are attributable to the living matter.

Now, the species of all living extinct quickly under influence of the construction activity of people. Moreover, this process is ten thousand times, and in some cases, a hundred thousand times more intensive than before. The species do not simply extinct. The entire structure of the living matter changes as influenced by the construction technologies. A forecast of different variants of anthropogenic hazards (climate change, planet desertification, failures of action of the system-base principle of Le Chatelier-Braun, i.e. the "Equilibrium Law") has shown that proceeding from the exhaustion of natural resources and environment pollution, the world disaster is a possibility that can be evaded through stabilization of population endowment and industry volume, motivation of agricultural development [27]. The implementation of the investment and construction projects without substantiation of ecological safety thereof also results in the change of energetic qualities of the bio-ecological system, which brings about the desertification of continents $(19 \%$ of the land surface is at risk). The foundation of both an immediate place of our life and of the economic development is dropping out. If earlier the social and economic adaptation followed the environmental changes, now it should precede these, since there is no margin of safety left with the nature, including a person as a biological subject [2].

According to Meadows group the mankind has already exceeded the limits of selfrenewal of the eco-systems of the Earth. The favorable scenarios of model of 1972 (with high or medium consumption level) have become unattainable since the world population will be 7.5 bln. by 2025, the consumption of natural resources and the destruction of environment correspond to the most unfavorable (basic) scenario. The time for implementation of the favorable scenarios has been missed out [12]. Meadows emphasizes, that if no "in-depth adjustment" of consumption of natural resources by the mankind is made in the nearest time, the collapse of the mankind in this or the other form is inevitable [25].

The Mesarovic and Takahara model [28] is distinguished by the dimension and detail of relations. It comprises more than 100 thous. equations describing the world system as a community of the regional systems, various scenarios of the world system development have been given consideration on the basis of this system.

The mathematic models of different levels are being presently developed, including components of natural interactions, processes in the system-level elements, self-regulatory mechanisms in nature, influence of human activity on the environment. The authors suppose that the complex of such models will help to evaluate the engineering solutions, activity of the cities, influence of construction and real property on the environment, variants of territories development and, even wider, the state and objective laws of development of ecoeconomical system "construction-vital activities environment".

\section{Results}

A significant spectrum of impacts is attributed to the negative ecological effects regarding the life cycle of the construction produce: depletion of resources; pollution of atmosphere; pollution of water environment; topsoil demolition; landscape change; emergence of industry related landscapes; dangerous noise pollution; generation of waste; violation of ecological 
equilibrium in the eco-system; extinction, degradation, suppression of vegetation; variation of hydro geological condition; variation of the stressed state of the beds of the Earth and other direct and indirect effects.

The incorporation of systems of ecological assessment of the construction produce throughout the life cycle demands a careful ecological investigation and assessment of safety at all stages of the construction produce life cycle, periodic ecological monitoring of "construction-vital activities environment" system.

The non-metallic natural resources, including clays, sand, limestone, chalk, crushed stone, coarse sand, stone, etc., are referred to as the primary source of material resources for the construction operations and a specific object of ecological investigation. The non-metallic raw materials hold a share of $62.9 \%$, including $58.1 \%$ of construction materials in total volume and structure of extraction of commercial minerals [29].

The annual volume of construction materials is $163 \mathrm{bln}$. $\mathrm{t}$ /year, including $79.7 \mathrm{bln}$. $\mathrm{t}$ /year of crushed stone, $71.4 \mathrm{bln}$. t/year of sand. The extraction thereof exceeds the total extraction of metallic raw materials and energy feedstock put together more than 1.5 times (104 bln. $\mathrm{t} /$ year). The extraction of commercial minerals increases by $9.98 \%$ per year.

The field of application of non-metallic construction materials includes production of concrete (35-40\%), road construction (30-35\%), construction operations (15-20\%). The share of non-metallic materials in the prime cost of, e.g., the reinforced-concrete items ranges from 10 to $15 \%$ depending on the type of produce. At that, the interest to non-metallic construction materials grows every year; the demand and consumption are on the rise according to the conducted market analysis.

The construction materials industrial enterprises extract more than 20 types of commercial minerals occupying annually 15 thous. ha of land, $90 \%$ of open pits in our country belong to the construction industry. The open-pit extraction of commercial minerals has a significant negative impact on the environmental situation in the area of mining. It brings about a noticeable aggravation of ecological situation. A direct demolition of local natural ecosystems comes forward as the main type of impact of the open-cut mining. In this case, according to experts about $25 \%$ of materials go to production waste [30].

The factories of construction industry for production of cement, asbestos-cement products, asphalt-concrete, limestone, woodworking works, limestone and chemical production facilities, factories for production of roofing and insulation materials, plants for fabrication of expanded-clay aggregate, bricks, ready-mixed concrete, precast reinforced concrete products, integrated house-building factories, etc. are the potent pollutants of the environment. The cost of the fixed assets of the construction materials industry amounts to $2.8 \%$ of the cost of all production assets of the country.

The construction is accompanied by a great amount of construction waste; around 7 tons of waste is generated in the course of erecting one house in Europe. The share of construction industry in the total volume of generated waste in general in the Russian Federation is about $0.4 \%$. The structure of construction waste with respect to generation sources looks as follows: repair $-62 \%$, demolition $-23 \%$, reconstruction $-11 \%, 37$ construction industry $-3 \%$, new construction $-1 \%$. The widespread types of construction waste include brick, concrete and reinforced concrete, littered soil, asphalt, wood, stone materials. The biggest share in the composition of construction waste, about $88 \%$, belongs to concrete, reinforced concrete and brick.

The industry of construction materials is one of the most fuel- and energy-intensive (more than $16 \%$ in the structure of expenses), as well as load-intensive branches of economy: the transport operations of the construction cargoes amount to about $25 \%$ in the total volume of freight activity by rail, road and water means of transportation. The production of construction materials, parts and articles is associated with the emission of dust, gas, soot, generation of various types of waste. In our country they produce $8.1 \%$ of air basin 
contaminants (whilst the road transport produces 13.3\%, enterprises of non-ferrous and ferrous metallurgy produce 10.5 and $24 \%$, thermal power plants produce $29 \%$ ). For instance, the emissions of production-induced cinder in the course of cement production make about $53,370 \mathrm{mln}$. t/year (2 times more than during iron smelting). The hydro technical, underground and transportation construction, construction of solid waste landfills infringe the ecological equilibrium, changes the environment. However, the quality of people' life, its comfort are determined not by the quantity of material benefits, but by the quality of environment too, wherein the people have to live, work and rest.

\section{Discussion}

It is now clear since long that apart of economic viability it is necessary to take into account the ecological safety of the process chain of extraction and processing of mineral raw materials. The question is not about the pre-eminence of ecology without economic development, which will bring about the poverty. The point is that the eco-economical equilibrium requires not only the new "permissive" technologies, but also increasing the share of expenses for environmental protection measures, which makes $30-50 \%$ of the capital investments for construction of the industrial facility in the developed countries [31-32].

Let us recall that the factories of the construction materials industry can be divided into five classes by the degree of hazard for environment:

I (the most hazardous) - big cement plants, plants for production of other binding materials (kilning of magnesium carbonate, dolomite, etc.);

II - factories for production of gypsum, asbestos, lime, asphalt concrete, wood-particle boards and wooden fiberboards on polymer resins;

III - factories for production of asbestos-cement, concrete and reinforced-concrete products, materials from TPP waste;

IV - factories for production polymer materials, faience and porcelain articles, ceramic and sand-lime brick;

$\mathrm{V}$ - factories for extraction and processing of stone, cane-fiber board, fiberboard, joinery, parquet-work, etc.

The commencement of construction is related to the earthwork. The construction organizations within the boundaries of Moscow only process 25-28 mln. tones of soil per year. The stockpiles of removed soil at the places of location thereof destroy the natural landscape, change the morphology of the areas of earth's surface, abolish vegetation, contribute to erosion and exclude the territories from economic turnover for long periods of time. The environment shall be regarded as a receiver of pollutants and waste being generated as a result of construction activity. The excavation and transportation of soil bring about the contamination of air with dust and exhaust gas from the engines of vehicles. A high level of pollution of air, water and soil is observed in the areas of construction, especially, industrial construction. It happens at all stages of construction produce life cycle (Table 1).

As we can see the ecological situation as a result of construction activity becomes worse from year to year and is on the brink of being disastrous. The action of Vernadsky law begins from some losses in the living matter, which will be followed by the avalanche destruction of the entire biogeochemical system [32]. The preservation of natural biosystems is announced as a strategic goal, actually, protection of its one element only, a human being is provided, which is not already the element of natural biota. Therefore, the regulatory actions of the nature protection activities in the industry have an abstract character. 
Table 1. Influence of construction produce on the environment taking into account life cycle.

\begin{tabular}{|l|l|}
\hline \multicolumn{1}{|c|}{$\begin{array}{c}\text { Stage of life cycle of construction } \\
\text { produce }\end{array}$} & \multicolumn{1}{|c|}{ Basic types of environmental impact } \\
\hline Extraction of raw materials & $\begin{array}{l}\text { Depletion of resources. Distortion of landscape. Damage to } \\
\text { eco-systems }\end{array}$ \\
\hline $\begin{array}{l}\text { Fabrication of construction materials, } \\
\text { articles, structural elements }\end{array}$ & Harmful emissions. Power consumption. Waste \\
\hline $\begin{array}{l}\text { Design and survey work. Building } \\
\text { roads and open pits }\end{array}$ & $\begin{array}{l}\text { Power consumption. Pollution of environment. Waste } \\
\text { generation }\end{array}$ \\
\hline Construction site organization & $\begin{array}{l}\text { Distortion of immediate runoff. Erosion of soil, change of } \\
\text { landscape. Generation of debris and driving of contaminated } \\
\text { road vehicles. }\end{array}$ \\
\hline $\begin{array}{l}\text { Construction: transportation, handling } \\
\text { operations, construction equipment } \\
\text { operation }\end{array}$ & $\begin{array}{l}\text { Pollution of atmospheric air, soil, subsoil water. Noise } \\
\text { pollution. Power consumption }\end{array}$ \\
\hline $\begin{array}{l}\text { Construction: welding, insulating, } \\
\text { roofing and finishing operations }\end{array}$ & $\begin{array}{l}\text { Harmful emissions into environment (gas, dust, etc.). Power } \\
\text { consumption }\end{array}$ \\
\hline $\begin{array}{l}\text { Construction: stone and construction } \\
\text { works }\end{array}$ & $\begin{array}{l}\text { Generation of waste and dust pollution of air. Vibration and } \\
\text { noise loads. Power consumption }\end{array}$ \\
\hline Operation of real property & $\begin{array}{l}\text { Harmful emissions. Influence on health of people. Power } \\
\text { consumption }\end{array}$ \\
\hline Demolition of real property & $\begin{array}{l}\text { Generation of waste in the course of housebreaking. Pollution } \\
\text { of environment. Distortion of landscape }\end{array}$ \\
\hline
\end{tabular}

It is necessary not only to make tougher the state control of carrying out measures of remediation of the disturbed soils and safeguarding environment by business, but also to channel significant capital investments for preservation of all still surviving elements of the natural biota. The amount of about $160 \mathrm{bln}$. dollars will become the socially warrantable expenditure for its saving by 2025. Considering the species disappear from the earth's surface at the rate of one species per day, it appears that even now the world-wide required expenses for saving the species equal approximately $30 \mathrm{bln}$. dollars per year [2].

\section{Conclusions}

The quality of construction depends directly on correct setting and solving the ecological tasks and permanent assessment of impacts on the environment at all stages of the project life cycle. The intensity and versatility of these impacts in many respects have already exceeded the rate of adaptation and stability of natural systems (e.g., it is no more possible restore the eco-system of Aral sea). It has resulted in the critical situations in the techno sphere of the Russian cities, which is attributable to the process of degradation of the environment. The urban planning continues to proceed without consideration of ecological requirements, actually in a chaotic manner. It is necessary to provide an adequate ecological monitoring of how much has been "eaten away" already and what is left. The natural and resource potential should not be lower than the level of resources requisition and the rate of 
changing environment for people's habitation. Otherwise, the anthropogenic distortions will appear bringing about the disasters.

This analysis of the construction industry impact on the environment has revealed the following. The urbanized territories exist under continuing external human impact on the eco-system, which is intensively operated thereby. The general condition of such territory is critical, and sometimes it is disastrous. The vegetation mantle of urban territories decreases sharply and changes as a result of construction. A desertification around the cities increases. A high degree of benzopyrene, formaldehyde, dust or soot and other harmful substances is present therein. The dust pollution, gas and heat air pollution take place. Water and soils become polluted as a result of emissions of industry, accumulation of municipal service waste on the urbanized territory. An absence of ecological reserve in order to bring the rate of exploitation of natural systems to an equilibrium with the intensity of self-restoration thereof have become a response of the eco-systems to the inefficient nature management and anthropogenic pressure. Thus, a load on the environment continues to grow in Russia, while the development of construction industry does not meet the objectives of sustainable development under conditions of the growing rate of demand for the raw materials despite a declared ecological efficiency.

\section{References}

1. S.M. El-Haggar, Sustainable Industrial Design and Waste Management: Cradle-tocradle for Sustainable Development (Elsevier, Academic Press, Amsterdam, 2007) https://doi.org/10.1016/B978-012373623-9/50005-8

2. N.F. Rejmers, Hopes for the Survival of Mankind Conceptual Ecology (Rossija molodaja, Moscow, 1992)

3. E. Smirnova, Espacios 39(22) (2018).

4. R.V. Ralegaonkar, M.V. Madurwar, \& V.V. Sakhare, Architecture and Design: Breakthroughs in Research and Practice (IGI Global, Hershey, PA. 2019) DOI: 10.4018/978-1-5225-7314-2.ch024

5. B. Commoner, The Closing Circle: Nature, Man, and Technology (Knopf, New York, 1971)

6. R. Hillary, ISO 14001: Case studies and practical experiences (Routledge, London, 2017)

7. A.C. Affam, E.H. Ezechi, Handbook of Research on Resource Management for Pollution and Waste Treatment (IGI Global, Hershey, 2019) DOI: 10.4018/978-1-79980369-0

8. A.N. Tetior, Ecocity: problems, solutions (NIA-Priroda, Moscow, 2005)

9. S. M. Kaufman, Metropolitan Sustainability: Understanding and Improving the Urban Environment (Woodhead Publishing Limited, Cambridge, 2012) https://doi.org/10.1533/9780857096463.1.40

10. M. Mbala, C. Aigbavboa, J. Aliu, Advances in Human Factors, Sustainable Urban Planning and Infrastructure, Advances in Intelligent Systems and Computing (Cham, Springer, 2019) https://doi.org/10.1007/978-3-319-94199-8_11

11. E. Smirnova, V. Gorohov, Monitoring and waste management in megacities (SPbGASU, Saint Peterburg, 2019)

12. N. Silver, Finance, Society and Sustainability: How to Make the Financial System Work for the Economy, People and the Planet (Palgrave Macmillan, London, 2017)

13. S. Barles, J. of Environ. Plann. Manag. 53(4), 439-455 (2010) 
14. N. Ghimire, R.T. Woodward, Ecol. Econ. 89, 73-81 (2013)

15. C. Salazar, J. Rand, J. of Environ. Plann. Manag. 253, 109705 (2020)

16. M.M. Rahman, J. of Environ. Plann. Manag. 253, 109742 (2020)

17. A. Kasman, Y. Duman, Econ. Modell. 44, 97-103 (2015)

18. B. Dogan, O. Deger, Int. J. Energy Econ. Policy 6(4), 806-813 (2016)

19. W. Cowan, T. Chang, R. Inglesi-Lotz, R. Gupta, Energy Policy 66, 359-368 (2014)

20. M. Slesarev, N.D. Dap, MATEC Web of Conf. 191, 04022, 1-8 (2018) https://doi.org/10.1051/matecconf/201819604022

21. E. Smirnova, V. Zaikin, E3S Web of Conf. 91, 05030, 1-12 (2019) https://doi.org/doi: $10.1051 / \mathrm{e} 3$ sconf $/ 20199105030$

22. A. Larionov, E. Nezhnikova, ARPN J. of Eng. and Appl. Sc. 11(3), 2023-2029 (2016)

23. A. Larionov, E. Nezhnikova, Int. J. of Appl. Eng. Res. 11(6), 4433-4439 (2016)

24. M.Y. Slesarev, V.I. Telichenko, IOP Conf. Ser.: Mater. Sc. and Eng. 456, 012126 (2018) https://doi.org/10.1088/1757-899X/456/1/012126

25. D. Meadows, J. Randers, D. Meadows, Limits to Growth. The 30-Year Update (Earthscan, London, 2005)

26. V.I. Vernadsky, Biosphere and Noosphere (Airis-Press, Moscow, 2012)

27. K.S. Schmitz, Ecology. Physical Chemistry: Multidisciplinary Applications in Society (Elsevier, Amsterdam, 2018) https://doi.org/10.1016/B978-0-12-800513-2.00005-X

28. M.D. Mesarovic, Y. Takahara, General Systems Theory: Mathematical Foundations (Academic Press, New York, 1975)

29. V. Augiseau, S. Barles, Resour. Conserv. and Recycl. 123, 153-164 (2017)

30. R. Heinberg, The End of Growth: Adapting to Our New Economic Reality (New Society Publishers Gabriola Island, BC, 2011)

31. A. Sayigh, Sustainability, Energy and Architecture: Case Studies in Realizing Green Buildings (Elsevier, Amsterdam, 2014)

32. R. Proctor, Sustainable Design Book (Laurence King Publishing Ltd, London, 2015) 